\title{
Determining the Unsaturated Hydraulic Conductivity of Remoulded Loess with Filter Paper Method and Soil Column Seepage Test
}

\section{Wenwu Chen}

Lanzhou University

Quanquan Jia ( $\nabla$ jiaqq2013@lzu.edu.cn)

Lanzhou University https://orcid.org/0000-0003-2246-8563

Peng Liu

Lanzhou University

Yanmei Tong

Lanzhou University

\section{Research Article}

Keywords: unsaturated hydraulic conductivity, remoulded loess, filter paper method, instantaneous profile method, statistical models

Posted Date: June 24th, 2021

DOI: https://doi.org/10.21203/rs.3.rs-548702/v1

License: (c) (i) This work is licensed under a Creative Commons Attribution 4.0 International License.

Read Full License

Version of Record: A version of this preprint was published at Environmental Earth Sciences on November 27th, 2021. See the published version at https://doi.org/10.1007/s12665-021-10100-2. 


\section{Determining the unsaturated hydraulic conductivity of remoulded}

\section{2 loess with filter paper method and soil column seepage test}

3 Wenwu Chen ${ }^{\mathrm{a}, \mathrm{b},{ }^{*}, \text { Quanquan Jia }}{ }^{\mathrm{a}, \mathrm{b}}$, Peng Liu ${ }^{\mathrm{a}, \mathrm{b}}$, Yanmei Tong ${ }^{\mathrm{a}, \mathrm{b}}$

$4 \quad{ }^{a}$ Collage of Civil Engineering and Mechanics, Lanzhou University, Lanzhou, Gansu 730000, China.

5 Email: sungp@1zu.edu.cn (Wenwu Chen); jiaqq2013@1zu.edu.cn (Quanquan Jia);

6 pliu16@1zu.edu.cn (Peng Liu); tongym13@1zu.deu.cn (Yanmei Tong).

$7 \quad \mathrm{~b}$ Key Laboratory of Mechanics on Disaster and Environment in Western China of Ministry of

8 Education, Lanzhou University, Lanzhou, Gansu 730000, China.

$9 \quad *$ Corresponding author:

Prof. Wen-wu Chen

11 Email: sungp@,1zu.edu.cn

School of Civil Engineering and Mechanics, Lanzhou University, Rd 222 Tianshui, Lanzhou, Gansu 730000, China.

\section{Abstract}

Loess is very widely distributed, and the unsaturated hydraulic conductivity of loess is related to many engineering issues. In order to determine the unsaturated hydraulic conductivity of remolded loess more conveniently and at a lower cost, filter paper test and soil column seepage test were carried out. The results indicate that in the one-dimensional soil column seepage process, the unsaturated hydraulic conductivity of loess increases with the increase of the volumetric water content, and as the seepage time continues, the unsaturated hydraulic conductivity of loess at different depths gradually becomes uniform. The changes in the microstructure indicate that the collapsible settlement will occur during the seepage process, which will reduce the unsaturated 
hydraulic conductivity of the underlying loess to a certain extent. Compared with the experimental results, the soil hydraulic conductivity curve (SHCC) obtained by the van Genuchten-Mualem model (VG-M model) underestimates the magnitude of unsaturated hydraulic conductivity in the part with a low volumetric water content $(<20 \%)$. and the Childs \& Collis-George model (CCG model) has more consistent results with the experimental results because it is based on more segments of the soil-water characteristic curve (SWCC).

Keywords : unsaturated hydraulic conductivity, remoulded loess, filter paper method, instantaneous profile method, statistical models.

\section{Introduction}

The unsaturated hydraulic conductivity (also termed as unsaturated permeability coefficient) of soil is one of the primary soil parameters, which is directly related to many engineering issues, such as landslides and foundation settlement caused by rainfall infiltration, design of irrigation and drainage system, and environmental risk assessment (Fredlund and Rahardjo, 1993; Gribb, et al., 2004; Rahimi, et al., 2010). The soil in nature (such as loess) is mostly in an unsaturated state, and the hydraulic conductivity of unsaturated soil is not a constant, but a function of suction or water content. The relationship between unsaturated hydraulic conductivity and suction or water content is usually expressed in the form of $K$ function expression or soil hydraulic conductivity curve (SHCC).

There are many methods to determine unsaturated hydraulic conductivity, but generally it can be summarized into direct and indirect methods. The direct method refers to direct measurement in laboratory or field test, such as instantaneous profile methods (Richards and Weeks, 1953), constant head method (Klute, 1972), constant flow method (Olsen, 1994), centrifuge method (Nimmo, et al., 1987), and outflow method (Gardner, 1956) etc. The indirect method refers to obtaining unsaturated 
hydraulic conductivity through empirical models and statistical models, which are mainly based on saturated hydraulic conductivity (Gardner, 1958), pore size distribution of the soil (Kunze, et al. 1968; Rosas, et al., 2015), and soil-water characteristic curve (van Genuchten, 1980; Ye, et al., 2014). The main models are shown in Table 1.

The instantaneous profile method (IPM) is a more commonly used direct method, first proposed by Richards and Weeks (1953). The technique refers to the fact that profile of suction is obtained by several tensiometers arranged along a soil column, independent measurement with conservation of mass in different intervals, and then the hydraulic conductivity in different intervals is calculated. Based on the principle of the IPM, many measurement techniques have been developed. Choo and Yanful (2000) calculated the hydraulic conductivity of the multilayer soils under evaporative conditions through tensiometer, TDR probe and finite element models. By monitoring the soil moisture content, suction, and wetting front advancing velocity during the seepage process, Li, et al. (2009) proposed the wetting front advancing method to calculate the unsaturated hydraulic conductivity of five soils. Ng and Leung (2012) developed a stress-controllable soil column device, and obtained the unsaturated hydraulic conductivity by controlling the stress in the soil column Wang, et al. (2014) conducted a seepage test on a one-dimensional loess column, combined with the SWCC of the soil sample independently obtained with a tensiometer, and calculated the SHCC of the loess sample. Leung, et al. (2016) modified the boundary flux of IPM, and the modified model also has good accuracy. Li, et al. (2020) combined a series of paleosol samples with filter paper into a soil column, and obtained the suction and water content of soil samples by the filter paper method, thereby calculating the unsaturated hydraulic conductivity of the paleosol samples.

The methods described in the above have their own advantages, However, some direct methods 
have certain requirements for the experimental equipment, which increases the cost and is not convenient enough, and if only the indirect method is used for calculation, the prediction result is not accurate enough due to the difference of soil properties. Therefore, a low-cost and easy-toimplement method to obtain the unsaturated hydraulic conductivity of the soil is necessary.

In this study, the SWCC of the soil sample independently measured by the filter paper method, and a series of water content reflectometers were arranged in a soil column to measure the water content profile during the seepage process of the one-dimensional soil column. The suction profile is calculated by the water content profile and SWCC, and then the unsaturated hydraulic conductivity of the soil sample is obtained based on the principle of IPM. The test results are compared with the results of different prediction models to explore their effectiveness.

\section{Materials and methods}

\subsection{Experimental material}

The soil specimen is a typical loess that deposited during Late Pleistocene period (i.e. Malan loess), taken from Lanzhou city, China (West side of Loess Plateau of China, Fig. 1). The physical parameters of the soil samples were also tested according to ASTM standards D854, D4318, and D2487. The basic physical parameters of Malan loess were shown in Table 2. The Grain size distribution of the loess specimen was shown in Fig. 2.

\subsection{Experimental steps and methods}

\subsubsection{Preparation of soil specimens}

The loess sample obtained is naturally air-dried, and the water content after natural drying is about $5 \%$. The dry density of undisturbed loess generally ranges from $1.25-1.65 \mathrm{~g} / \mathrm{cm}^{3}$ (Yao, et al., 2012), therefore, the median value of $1.45 \mathrm{~g} / \mathrm{cm}^{3}$ is taken as the dry density of the remoulded sample. Two 
types of remoulded loess samples are prepared. The loess used for the SWCC test is first placed in an oven $\left(105^{\circ} \mathrm{C}\right)$ for 12 hours to dry, and then a quantitative amount of distilled water is added to prepare different moisture content samples, and stored in a sealed bag for 24 hours to ensure uniform moisture diffusion. Then, the loess sample were placed into a cylindrical mould with an inner diameter of $4 \mathrm{~cm}$ and a height of $1 \mathrm{~cm}$ to form a specimen with dry density of $1.45 \mathrm{~g} / \mathrm{cm}^{3}$. The loess used for the soil column seepage test is directly placed in the designed cylindrical acrylic mould (inner diameter $47.8 \mathrm{~cm}$, height $100 \mathrm{~cm}$ ) by natural accumulation method in the natural air-drying state. After adding a certain amount of soil each time, gently ram the top of soil column to the calculated height (approximately $10 \mathrm{~cm}$ rise for every $26 \mathrm{~kg}$ added) to ensure that the dry density of the soil column is $1.45 \mathrm{~g} / \mathrm{cm}^{3}$ evenly. A total of sixteen parallel specimens were made for the SWCC test, and one loess column was used for the soil column seepage test.

\subsubsection{SWCC test}

The SWCC of soil specimen is determined by the filter paper method (ASTM D5298, Houston, et al., 1994, Likos and Lu, 2002). SWCC test is carried out with No.203 filter paper (produced by Hangzhou Xinhua Co., Ltd.), which has been proved to have high accuracy in filter paper technology (Chen, et al., 2018, Wang, et al., 2003). Before SWCC test, the filter paper was calibrated by determining the relationship between water content and suction. In order to better calibrate the filter paper in the whole suction range, a combination of salt solution method and pressure plate method was used for calibration. The salt solution method refers to the use of Kelvin's equation to calculate the relationship between suction and moisture content of filter paper after it is balanced in the vapor pressure environment formed by different concentrations of sodium chloride solution. And the specific test steps are carried out according to the method of Likos and Lu (2002). The 
111 pressure method is carried out with a pressure plate extractor $(1500 \mathrm{~F} 2$, manufactured by soil

112 moisture equipment company, U.S.). The filter paper calibration curve drawn according to the 113 calibration results is shown in Fig.3.

114 According to the calibration curve, the relationship between suction and the water content of the

115 filter paper can be obtained, as shown in Eq. (7):

$$
\lg \psi=\left\{\begin{array}{lc}
4.7786-0.0725 w_{f p} & w_{f p}<19.71 \\
3.9801-0.0315 w_{f p} & 19.71<w_{f p}<60.01 \\
2.6895-0.0100 w_{f p} & w_{f p}>60.01
\end{array}\right.
$$

116 Where $\psi$ is suction, $(\mathrm{kPa}) . \quad w_{f p}$ is filter paper water content, $(\%)$.

117 After calibration, the water content of the soil specimen is set from $1 \%$ to $25 \%$, and each gradient

118 is increased by $2 \%-3 \%$. The specimens were wrapped as shown in Fig. 4. After 20 days of

119 equilibration time, open the sealed box and weigh the filter paper to calculate its water content, and

120 retest the water content of the soil specimens. The filter paper test equilibration process requires a

121 constant ambient temperature, and the filter paper weighing process should not exceed $30 \mathrm{~s}$ (Wang,

122 et al., 2003). The SWCC of the soil specimen is obtained by the water content of the filter paper

123 after equilibrium and the calibration curve.

\subsubsection{Soil column seepage test}

In order to make the added water infiltrate evenly, a $10 \mathrm{~cm}$ thick quartz sand cover layer is set on the top of the soil column. Similarly, in order to facilitate the collection of exuded water, a $10 \mathrm{~cm}$ quartz sand cushion layer is designed at the bottom. Under natural rainfall conditions, the moisture content of the loess at the ground to a depth of $40 \mathrm{~cm}$ changes significantly ( $\mathrm{Li}$, et al., 2013, Lin, et 

at any cross section can be expressed as

$$
h=\frac{\psi}{\rho_{w} g}+z
$$

manufactured by Decagon, U.S.). The basic parameters of the probe are shown in Table 3. Before the test, calibrate the probe by preparing soil samples with different moisture content gradients, and then the probes were buried in the center of the soil column. The arrangement of the probes is shown in Fig.5.

To avoid ponding on the top of the soil column, a sprinkler was used to evenly add water to the top for a total of $1 \mathrm{~h}$, and add a total of $5 \mathrm{~L}$ of water to simulate a heavy rainfall process (rainfall in Lanzhou City is mainly manifested as concentrated heavy rainfall). And cover the tube immediately after water injection to prevent evaporation. Record the changes of water content at intervals of 3 days, 6 days, and 12 days.

\subsubsection{Calculation step}

Due to the velocity of the seepage is very slow, ignore the influence of velocity head. The total head where $h$ is total head, $z$ is elevation head, $\psi$ is suction head, $\rho_{w}$ is the density of water, and $g$ is gravitational acceleration.

Record the heads at $Z_{1}$ and $Z_{2}$ as $h_{1}$ and $h_{2}$ respectively, and take the $\left(h_{1}+h_{2}\right) / 2$ layer as the reference layer, then the amount of water $V$ passing through the plane can be expressed as

$$
V=\int_{0}^{\frac{\left(h_{2}-h_{1}\right)}{2}} \theta(z) A \mathrm{~d} x
$$

where $\theta(z)$ is the function between volumetric water content and depth, which can be obtained from the profile of water content. A is the cross-sectional area of the soil column. The amount of water change from time $t_{1}$ to time $t_{2}$ is 


$$
\Delta V=\int_{0}^{\frac{\left(h_{2}-h_{1}\right)}{2}} \theta_{t_{1}}(z) A \mathrm{dz}-\int_{0}^{\frac{\left(h_{2}-h_{1}\right)}{2}} \theta_{t_{2}}(z) A \mathrm{dz}
$$

150

and seepage velocity $v$ is

$$
v=\frac{\Delta V}{A \Delta t}
$$

151 Linearize the hydraulic gradient $i$, which can be expressed as

$$
i=\frac{1}{2}\left(\frac{h_{1-1}-h_{1-2}}{z_{2}-z_{1}}+\frac{h_{2-1}-h_{2-2}}{z_{2}-z_{1}}\right)
$$

where the first digit in the subscript indicates time, and the second digit indicates depth, that is, $h_{1-2}$ indicates the head with time $t_{1}$ and depth $Z_{1}$.

According to Darcy's law, the hydraulic conductivity is the ratio of $v$ and $i$.

\section{Results and discussion}

\subsection{SWCC and curve fitting}

The results obtained by the filter paper method are calibrated by Eq. (7) and plotted in the suctionwater content relationship diagram. In order to obtain a more continuous SWCC, Eq. (1) and Eq. (2) (i.e., the VG model and FX model) are used to fit the obtained data, and the results are shown in Fig. 6. Table 4 is fitting parameters.

From the fitting results, when describing the SWCC of the remoulded loess measured by the filter paper method, the Adj. $\mathrm{R}^{2}$ of both models is above 0.93 . But as far as the test results are concerned, the FX model is more accurate for fitting the data of the high water content ( $>30 \%)$ part and the low water content $(<15 \%)$ part. In the calculation of the IPM method, most of the data are concentrated in the moisture content range of $15 \%-30 \%$, so both models can be used for calculation.

\subsection{Profile of water content and suction}

Fig. 7a is the curve of moisture content with depth in different time obtained from the seepage test 
of soil column, that is, the profile of water content. And Fig. $7 \mathrm{~b}$ is the profile of suction based on VG model fitting curve. At the beginning of simulated rainfall infiltration, the water content of the surface loess changed significantly, but there was almost no change at a depth of $40 \mathrm{~cm}$. With the continuous infiltration of rainfall every day, the distribution of moisture in the soil column gradually becomes uniform. After one month, the moisture content is mainly concentrated at $15 \%-20 \%$.

\subsection{Calculation results}

Tables 5 to Table 8 show the calculation results based on profile of water content and SWCC, of which Table 5 and Table 6 are the results based on the VG model fitting curve, and Table 7 and Table 8 are the results based on the FX model fitting curve. The first digit of the serial number in the table represents the time period, I to IV represent the four time intervals of 1-4 d, 4-10 d, 10-22 $\mathrm{d}, 22-34 \mathrm{~d}$, and the second digit is the corresponding probe depth, 0 to 4 correspond to 0 to $40 \mathrm{~cm}$

\subsection{Variation of unsaturated hydraulic conductivity with seepage}

In order to analyze the migration and change law of the water in the soil column during the seepage process, the calculation results of the IPM based on VG model fitting curve are plotted in Fig. 8 as an example. From Fig. 8a, it can be seen that the variation of unsaturated hydraulic conductivity with depth of loess column has similar characteristics to the distribution of water content with depth in Fig. 7a. All of them gradually uniformed with the duration of seepage, that is, the unsaturated hydraulic conductivity values of the loess in each part gradually approached. Fig $8 \mathrm{~b}$ reflects the same law. The variation of depth below $20 \mathrm{~cm}$ shows that as the loess changes from dry to wet, that is, the process of increasing the water content, the hydraulic conductivity of the loess gradually increases. The surface loess from $0 \mathrm{~cm}$ to $10 \mathrm{~cm}$, the water content gradually decreases with the seepage process, and its hydraulic conductivity gradually decreases. 


\subsection{Microstructure}

The microstructure of soil samples after seepage test at different depths was investigated (Take three samples every $10 \mathrm{~cm}$ from $10 \mathrm{~cm}$ to $40 \mathrm{~cm}$, because they have similar rules, take a group of samples as an example to illustrate). Moreover, the obtained micrographs were binarized to reflect the porosity changes more intuitively, as shown in Fig. 9. Through analyses with ImageJ, the micrographs after binarization show that the porosity of the soil samples from $10 \mathrm{~cm}$ to $40 \mathrm{~cm}$ are $41.13 \%, 33.36 \%, 25.23 \%$, and $18.85 \%$, respectively. Although there is a certain error between the result of binarization and the actual situation, the change in porosity reflects a trend, that is, as the penetration depth increases, the large pores in the deep soil are filled, and the soil becomes denser. This phenomenon is caused by two reasons, one is that the soil at the bottom is denser due to its own weight, and the other is the collapsibility of loess. Lei (1987) think that the interparticle pores in loess are the main pore types that cause loess collapsibility, and that the pores of loess in Lanzhou area are mainly interparticle pores. When moisture penetrates into the soil, the connection force between particles is rapidly decreased under its own weight or a certain pressure, and the particles around the pores sink into the pores, and the particles rearrange and become compact, resulting in collapsibility. This indicates that the unsaturated seepage process of loess will be accompanied by the occurrence of collapsible settlement. And the change in the collapsible settlement of the soil column can be observed through the scale engraved on the acrylic cylinder. Fig. 10 shows the relationship between settlement displacement of the soil column and seepage time. It can be seen that with the passage of seepage time, the wetting front continues to advance downward, and the settlement of the soil continues to increase. However, due to the remodeling of the soil changes the original structure, the settlement displacement is not large, the maximum is only $11 \mathrm{~mm}$. Compared 
212 with remoulded loess, there are some root holes and wormholes in the undisturbed loess and a

213 smaller dry density of the undisturbed loess, so there will be more intense collapsibility. The

214 penetration of water in the soil is mainly promoted in the form of capillary wetting fronts, and

215 capillary water mainly exists in pores with a diameter of 0.002-0.5 mm. Collapsible settlement leads

216 to closure and reduction of capillary pores, making capillary water difficult to conduct. Since the

217 IPM is based on the conservation of mass to calculate the unsaturated hydraulic conductivity

218 between different sections of the soil column, the unsaturated hydraulic conductivity of the high

219 water content part is calculated from the upper cross section of the soil column, and the unsaturated

220 hydraulic conductivity of the low water content part is obtained from the lower cross section of the

221 soil column. This leads to the fact that when calculating with IPM, with the decrease of water content,

222 the decrease trend of the unsaturated hydraulic conductivity in the low water content part faster than

223 the high water content part. That is, the slope of SHCC in the low water content section is higher

224 than that in the high water content section.

$225 \quad 3.6$ Statistical models calculation

226 Compared with obtaining SHCC by experiment, indirect use of SWCC to obtain unsaturated

227 hydraulic conductivity is also a common method (Rahimi, et al., 2015). van Genuchten-Mualem

228 model (VG-M model) and Childs \& Collis-George model (CCG model) are the two most

229 commonly used prediction models. Compare the experimental results with the results of these two

230 models.

$231 \quad 3.6 .1$ VG-M model

232 The parameters in the VG-M model (i.e., Eq. 5) are determined by the SWCC (i.e., Fig. 6), and it

233 were determined according to the method described by van Genuchten (1980). The results are shown 
in Table 9.

The parameters calculated by different SWCC models are substituted into the VG-M model to obtain

SHCC, and Fig. 11 is a comparison of IPM data and VG-M model calculation results. The calculation results of the VG-M model reflect the same law as the soil column seepage test, that is, as the volumetric water content increases, the hydraulic conductivity increases. However, as the volumetric water content decreases, the slope of the SHCC increases, especially in the part where the volume water content is less than $15 \%$, the hydraulic conductivity changes by several orders of magnitude. In other words, when the loess is close to the dry state, the VG-M model considers it to be almost impermeable, this is obviously not normal. By comparison, the results of the two methods are more consistent in the part with a volumetric water content greater than $20 \%$. Where the volumetric water content is less than $20 \%$, the prediction result of the VG-M model is smaller than the test result of IPM. The experiment result conducted by Li et al. (2020) on undisturbed loess has a similar pattern.

\subsubsection{CCG model} water at a test temperature of $20^{\circ} \mathrm{C}$. The calculated results are shown in Table 10. A comparison of IPM data and calculated results of CCG model is shown in Fig. 11.

\subsubsection{Error analysis}

The root mean square error (RMSE) can measure the degree of consistency between the calculated values of different models and the experimental values. The smaller the value of RMSE, the closer the calculated value is to the experimental value, which indirectly indicates that the model is more 
applicable. The RMSE in this paper is calculated by Eq. (13), and the results are shown in Table 11.

$$
R M S E=\sqrt{\frac{\sum_{i=1}^{N}\left(\left|\ln x_{i}\right|-\left|\ln x_{0}\right|\right)^{2}}{N}}
$$

As far as this experiment is concerned, through RMSE analyses, for the prediction of unsaturated hydraulic conductivity, the CCG model is superior to the VG-M model in accuracy and precision based on the same kind of SWCC. Compared with the FX model, the VG model lacks a correction factor, which makes the description of the relationship between water content and suction in the low water content part (i.e. high suction part) inaccurate (Fayer and Simmons, 1995). As shown in Fig. 4, there are differences in the shape of the curves of the two models. Furthermore, the parameters of the VG-M model largely depend on the slope at the midpoint of the SWCC, so that the predicted value of the VG-M model and the experimental results will produce certain errors, while the CCG model divides SWCC into $N$ intervals, which can reduce errors caused by some intervals. The loess will collapse in the seepage process, and the porosity will change accordingly, which also leads to the error of the prediction model and the experimental results.

\section{Conclusion}

The unsaturated hydraulic conductivity of remolded loess was measured based on filter paper method and soil column seepage test. The method is easy to implement and very low cost. The results indicate that in the one-dimensional soil column seepage process, the unsaturated hydraulic conductivity increases with the increase of the volumetric water content. And as the seepage time continues, the unsaturated hydraulic conductivity of the loess at different depths gradually becomes uniform. The micrograph shows that with the seepage process, the loess will collapse, resulting in the change of the pore structure, which will reduce the unsaturated hydraulic conductivity of the 
underlying loess to a certain extent. As far as the RMSE between the prediction model and the results of this experiment is concerned, because the CCG model has more subdivisions for SWCC, the error

278 is relatively small. The prediction results of VG-M model will have a large error in the low volume water content $(<15 \%)$ part, and the lower the water content, the greater the error.

\section{Acknowledgements}

This work was supported by the National Key Research and Development Project (Grant No.

lzujbky-2020-it06).

\section{Conflict of interest statement}

On behalf of all authors, the corresponding author states that there is no conflict of interest.

286

287

\section{References}

ASTM D854-14 (2014) Standard Test Methods for Specific Gravity of Soil Solids by Water Pycnometer, ASTM International, West Conshohocken, PA ASTM D4318-17 (2017) Standard Test Methods for Liquid Limit, Plastic Limit, and Plasticity Index of Soils, ASTM International, West Conshohocken, PA ASTM D2487-17 (2017) Standard Practice for Classification of Soils for Engineering Purposes (Unified Soil Classification System), ASTM International, West Conshohocken, PA ASTM D5298-16 (2016) Standard Test Method for Measurement of Soil Potential (Suction) Using Filter Paper, ASTM International, West Conshohocken, PA

Chen W-W, Liu P, Liu W, Lin G-C, Xu H (2018) Suction tests on sliding soil in interface landslide based on filter paper method. Chinese Journal of Geotechnical Engineering 40: 112-117 DOI 10.11779/CJGE2018S1018

Choo LP, Yanful EK (2000) Water flow through cover soils using modeling and experimental methods. J Geotech Geoenviron Eng 126: 324-334 DOI 10.1061/(asce)1090-0241(2000)126:4(324)

Fayer MJ, Simmons CS (1995) midified soil-water retention functions for all matric suctions. Water Resources Research 31: 1233-1238 DOI 10.1029/95wr00173

Fredlund DG, Rahardjo H (1993) Soil mechanics for unsaturated soils John Wiley \& Sons, New york Fredlund DG, Xing A (1994) Equations for the soil-water characteristic curve. Can Geotech J 31: 521532 DOI 10.1139/t94-061

Gardner WR (1956) Calculation of capillary conductivity from pressure plate outflow data. Soil Sci Soc Am J 20: 317-320

Gardner WR (1958) Some steady states solutions of the unsaturated moisture flow equation with applications to evaporation from a water table. Soil Science 85: 228-232 
Gribb MM, Kodesova R, Ordway SE (2004) Comparison of soil hydraulic property measurement methods. J Geotech Geoenviron Eng 130: 1084-1095 DOI 10.1061/(asce)1090-0241(2004)130:10(1084) Houston SL, Houston WN, Wagner AM (1994) Laboratory filter paper suction measurements. Geotechnical Testing Journal 17: 185-194

Klute A (1972) The determination of the hydraulic conductivity and diffusivity of unsaturated soils. Soil Science 113: 264-276

Kunze RJ, Uehara G, Graham K (1968) Factors Important in the Calculation of Hydraulic Conductivity. Soil Sci Soc Am J 32: 760-765

Lei XY (1987) Pore types and collapsibility of loess in China. Science in China Series B 12: 1309-1318 Leung AK, Coo JL, Ng CWW, Chen R (2016) New transient method for determining soil hydraulic conductivity function. Can Geotech J 53: 1332-1345 DOI 10.1139/cgj-2016-0113

Li H, Li T-L, Jiang R-J, Fan J-W (2020) Measurement of unsaturated permeability curve using filter paper method. Rock and Soil Mechanics 41: 895-904 DOI 10.16285/j.rsm.2019.0360

Li P, Li T-L, Wang AD, Zhang Y-G, Liang Y, Zhao J-F (2013) In-situ test research on regularities of water migration in loess. Rock and Soil Mechanics 34: 1331-1339

Li X, Zhang LM, Fredlund DG (2009) Wetting front advancing column test for measuring unsaturated hydraulic conductivity. Can Geotech J 46: 1431-1445 DOI 10.1139/t09-072

Likos WJ, Lu N (2002) Filter paper technique for measuring total soil suction, Geology and Properties of Earth Materials 2002: Soil, Geology, and Foundations, Transportation Research Record 1786:120-128. Lin GC, Chen WW, Liu P, Liu W (2019) Experimental study of water and salt migration in unsaturated loess. Hydrogeol J 27: 171-182 DOI 10.1007/s10040-018-1861-8

Ng CWW, Leung AK (2012) Measurements of Drying and Wetting Permeability Functions Using a New Stress-Controllable Soil Column. J Geotech Geoenviron Eng 138: 58-68 DOI 10.1061/(asce)gt.19435606.0000560

Nimmo JR, Rubin J, Hammermeister DP (1987) Unsaturated flow in a centrifugal field: measurement of hydraulic conductivity and testing of darcy's law. Water Resources Research 23: 124-134

Rahimi A, Rahardjo H, Leong E-C (2010) Effect of hydraulic properties of soil on rainfall-induced slope failure. Engineering Geology 114: 135-143 DOI 10.1016/j.enggeo.2010.04.010

Rahimi A, Rahardjo H, Leong E-C (2015) Effect of range of soil-water characteristic curve measurements on estimation of permeability function. Engineering Geology 185: 96-104 DOI 10.1016/j.enggeo.2014.11.017

Richards LA (1931) Capillary conduction of liquids through porous mediums. Physics 1: 318-333

Richards SJ, Weeks LV (1953) Capillary conductivity values from moisture yield and tension measurements on soil columns. Soil Sci Soc Am J 17: 206-209

Rosas J, Jadoon KZ, Missimer TM (2015) New empirical relationship between grain size distribution and hydraulic conductivity for ephemeral streambed sediments. Environmental Earth Sciences 73: 13031315 DOI 10.1007/s12665-014-3484-2

van Genuchten MT (1980) A close-form equation for predicting the hydraulic conductivity of unsaturated soils. Soil Sci Soc Am J 44: 892-898 DOI 10.2136/sssaj1980.03615995004400050002x

Wang H, Li T-L, Fu Y-K (2014) Determining permeability function of unsaturated loess by using instantaneous profile method. Journal of Hydraulic Engineering 45: 997-1003 DOI 10.13243/j.cnki.slxb.2014.08.014

Wang Z, Yang J-X, Kuang J-J, An J-Y, Luo Y-D (2003) Application of filter paper method in field measurement of matric suction. Chinese Journal of Geotechnical Engineering 25: 405-405 
353 Yao Z-H, Chen Z-H, Huang X-F, Zhang S-J, Yang X-H (2012) Hydraulic conductivity of unsaturated 354 undisturbed and remolded Q3 loess. Chinese Journal of Geotechnical Engineering 34: 1020-1027

355 Ye WM, Wan M, Chen B, Chen YG, Cui YJ, Wang J (2014) An unsaturated hydraulic conductivity model 356 for compacted GMZ01 bentonite with consideration of temperature. Environmental Earth Sciences 71: 357 1937-1944 DOI 10.1007/s12665-013-2599-1 
Figures

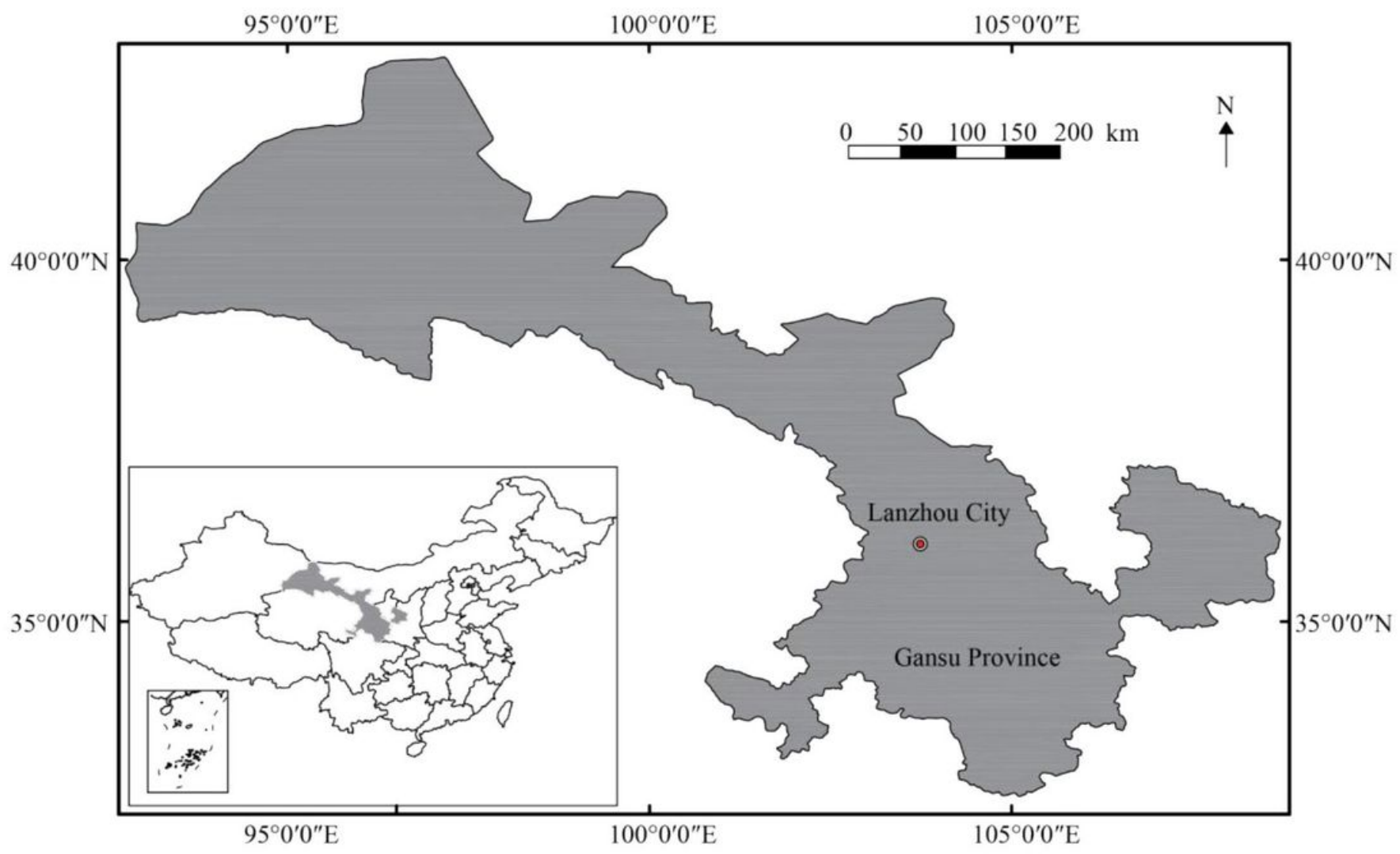

\section{Figure 1}

The location of the Lanzhou City. 


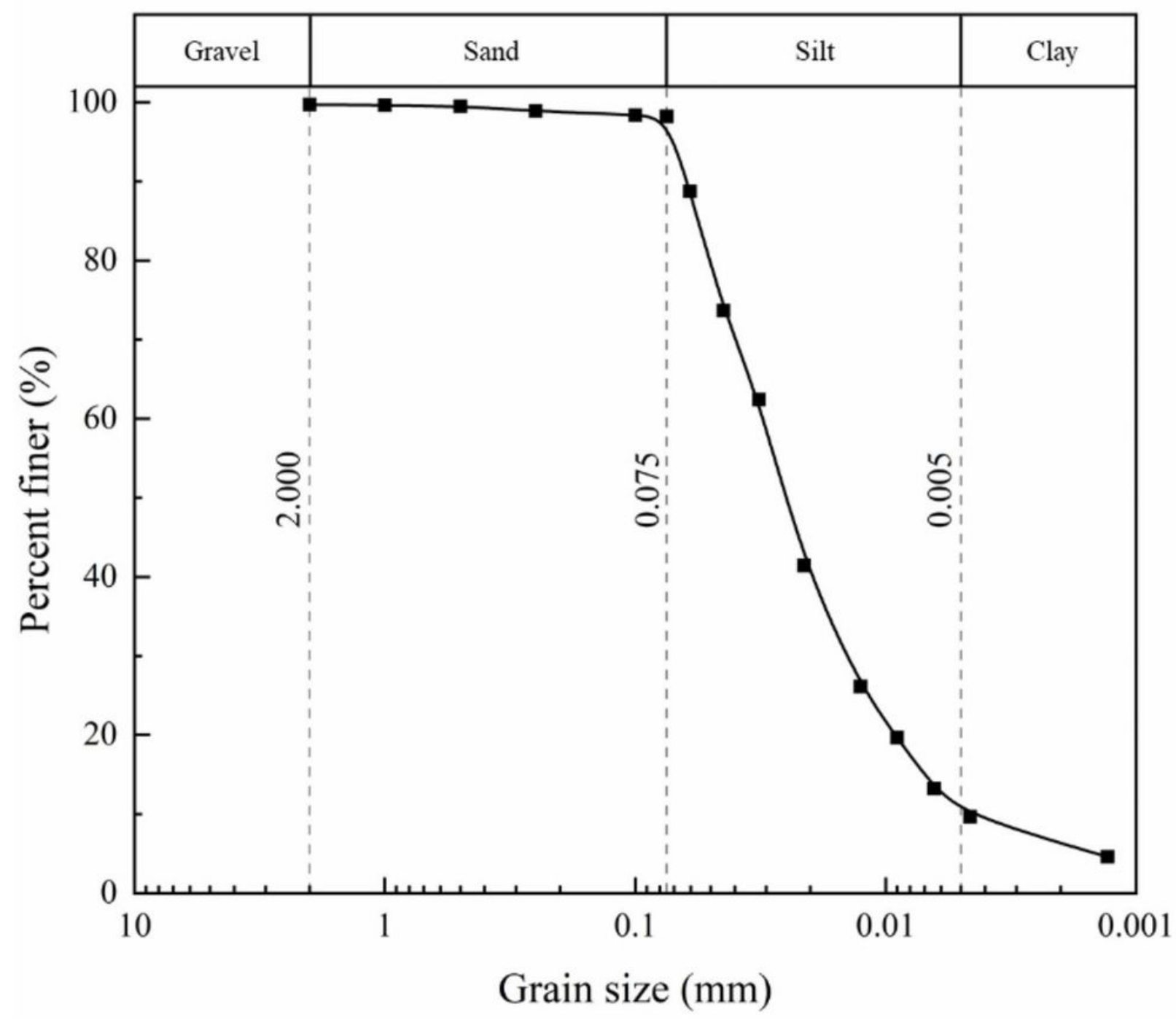

Figure 2

Grain size distribution of the loess. 


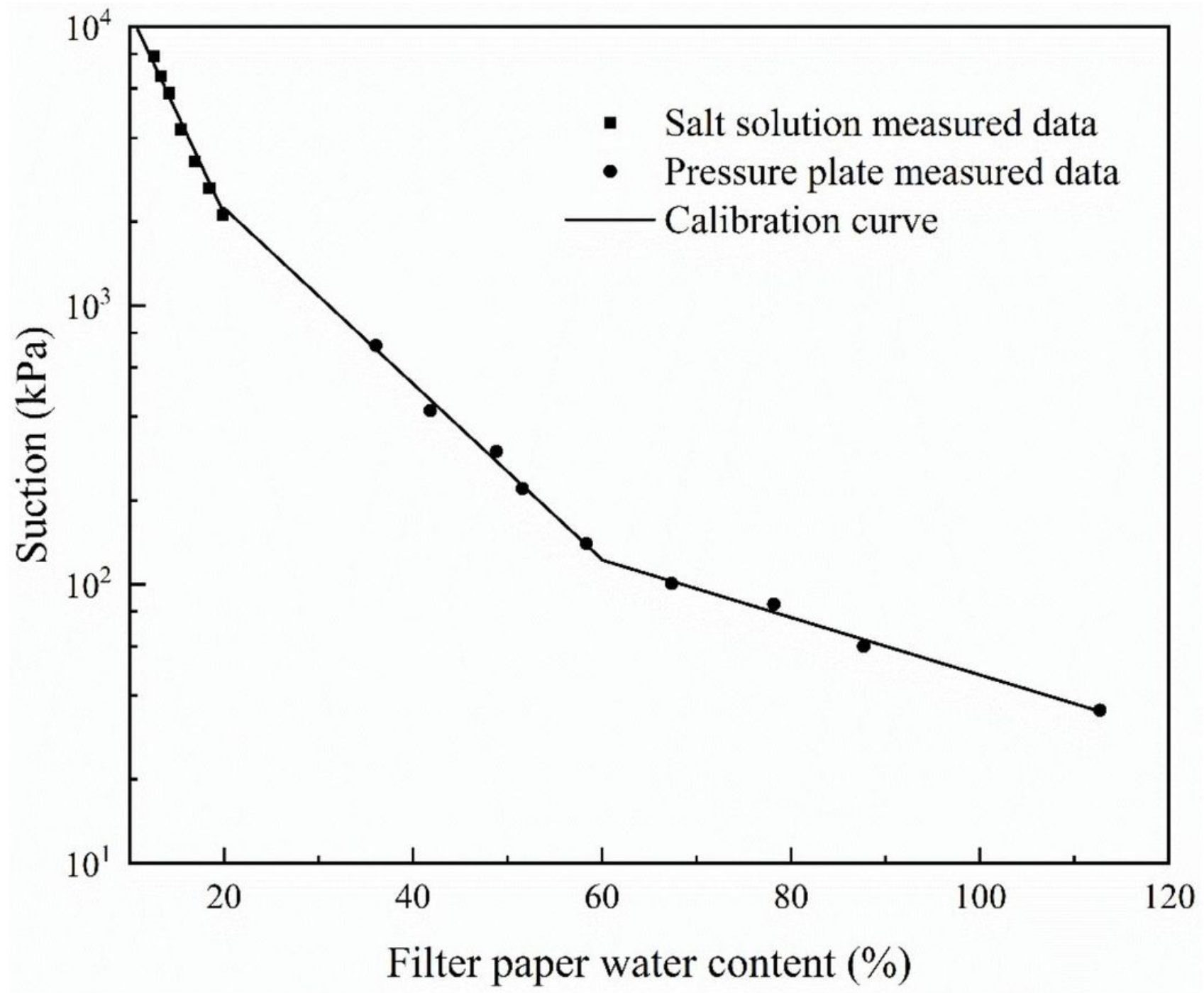

Figure 3

Filter paper calibration curve 

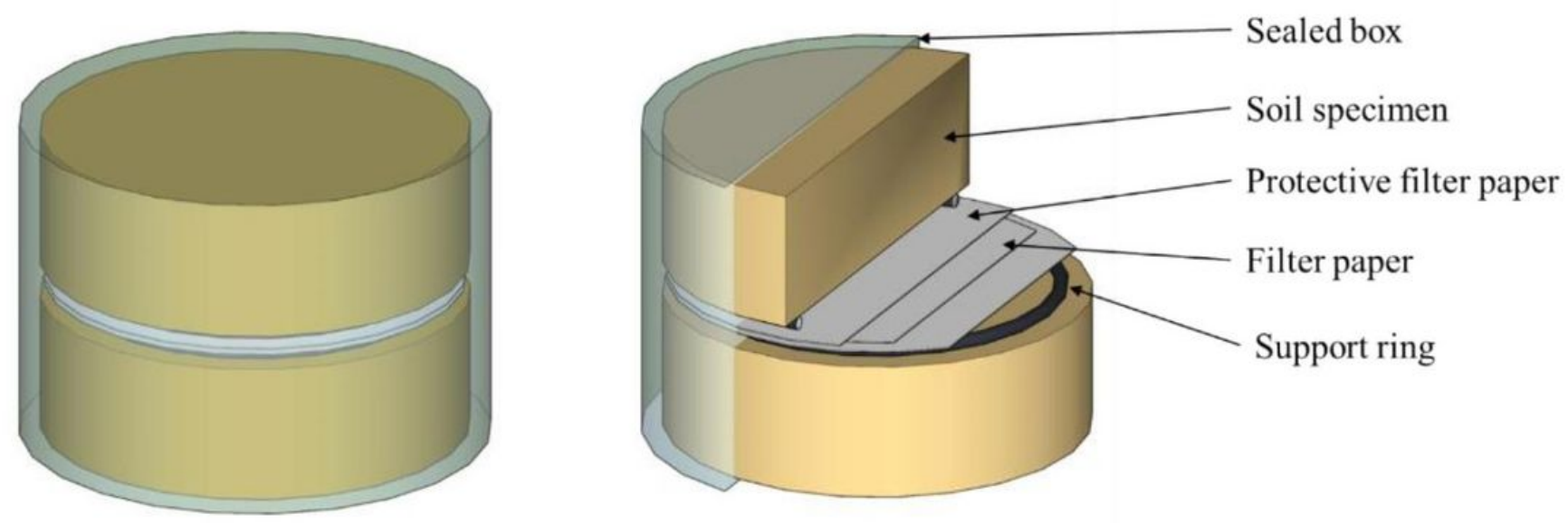

Figure 4

Sketch of filter paper test.
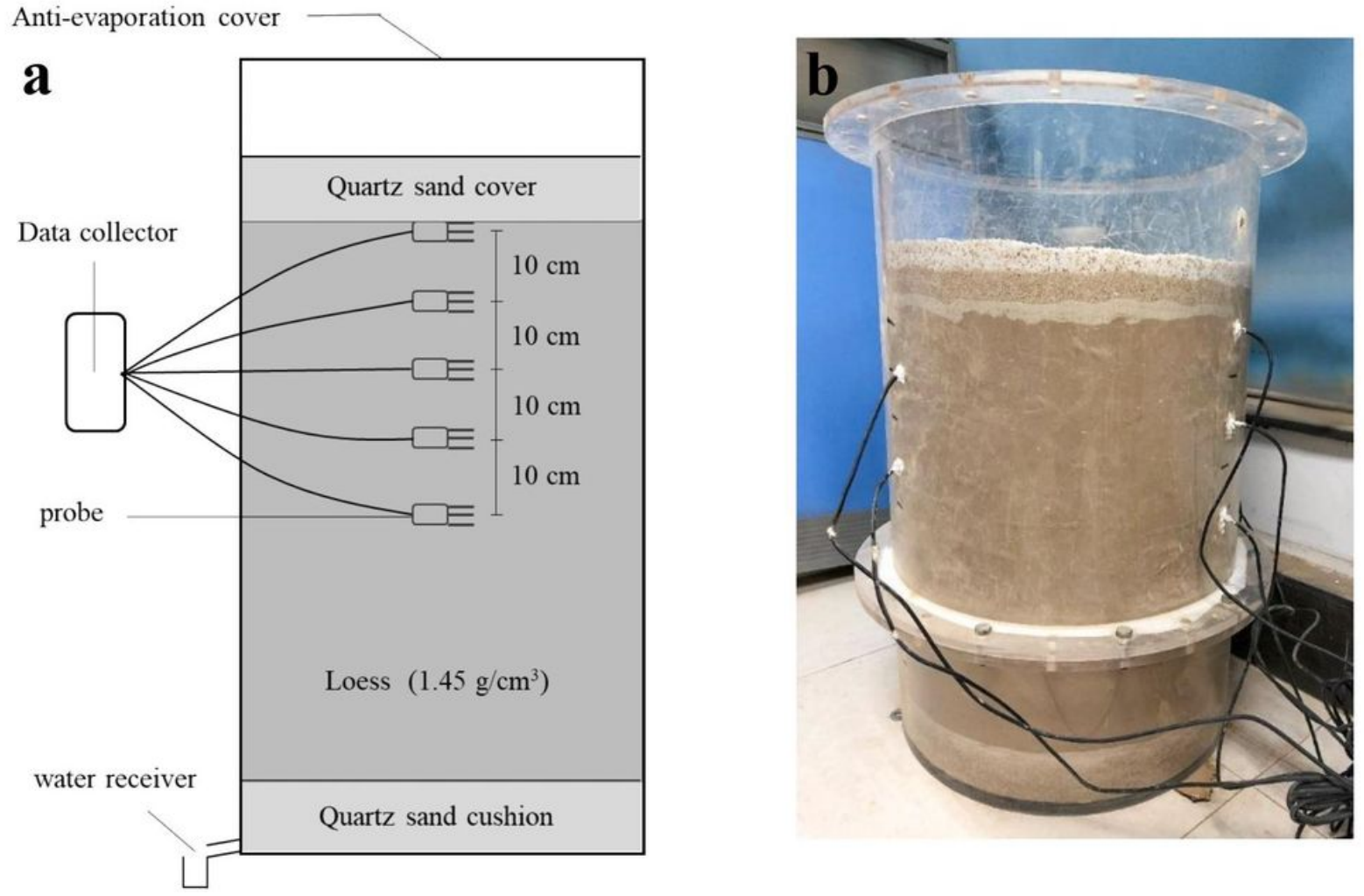

Figure 5

Sketch (a) and picture (b) of soil column test. 


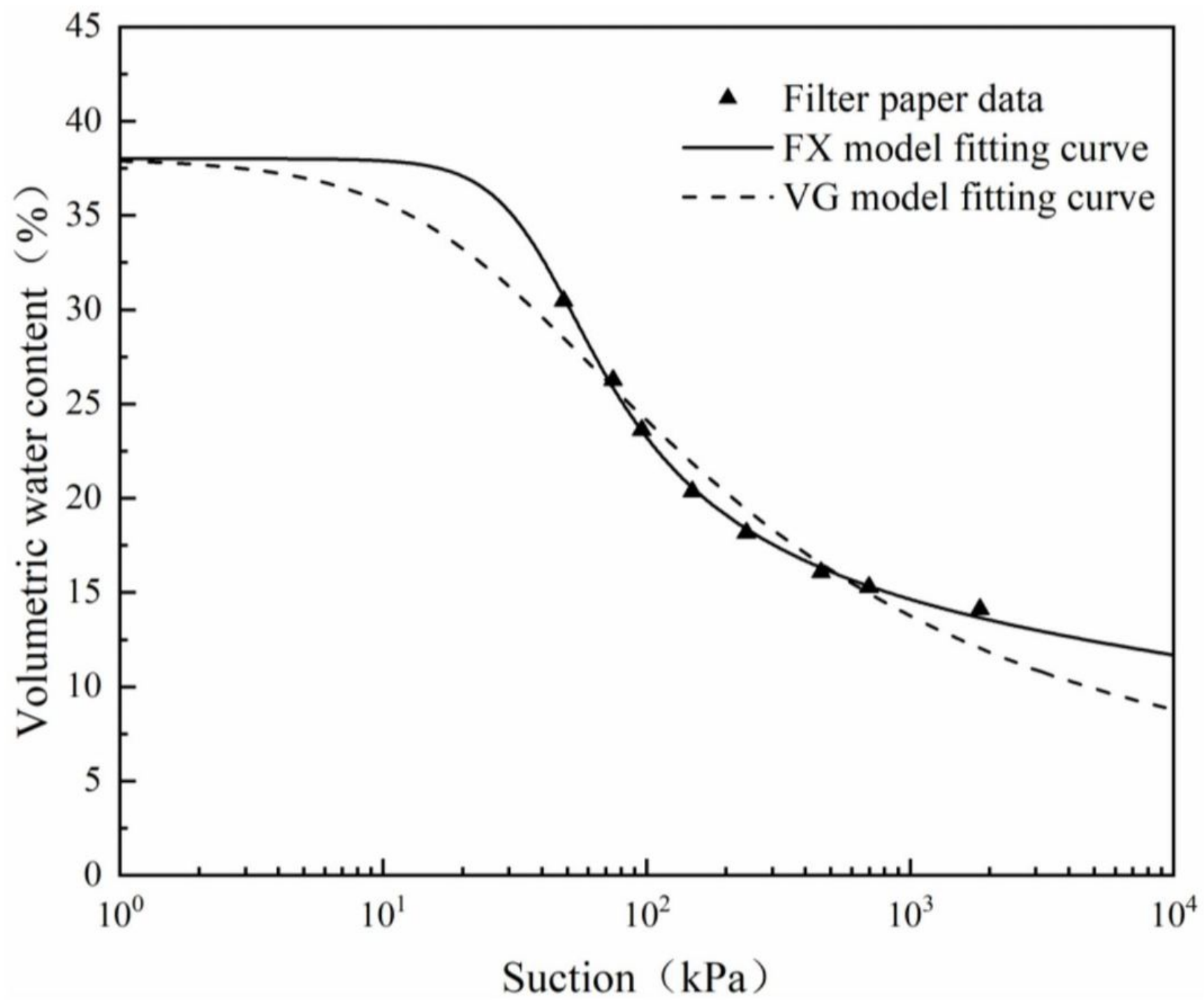

Figure 6

Test data and fitting curves. 


\section{a}

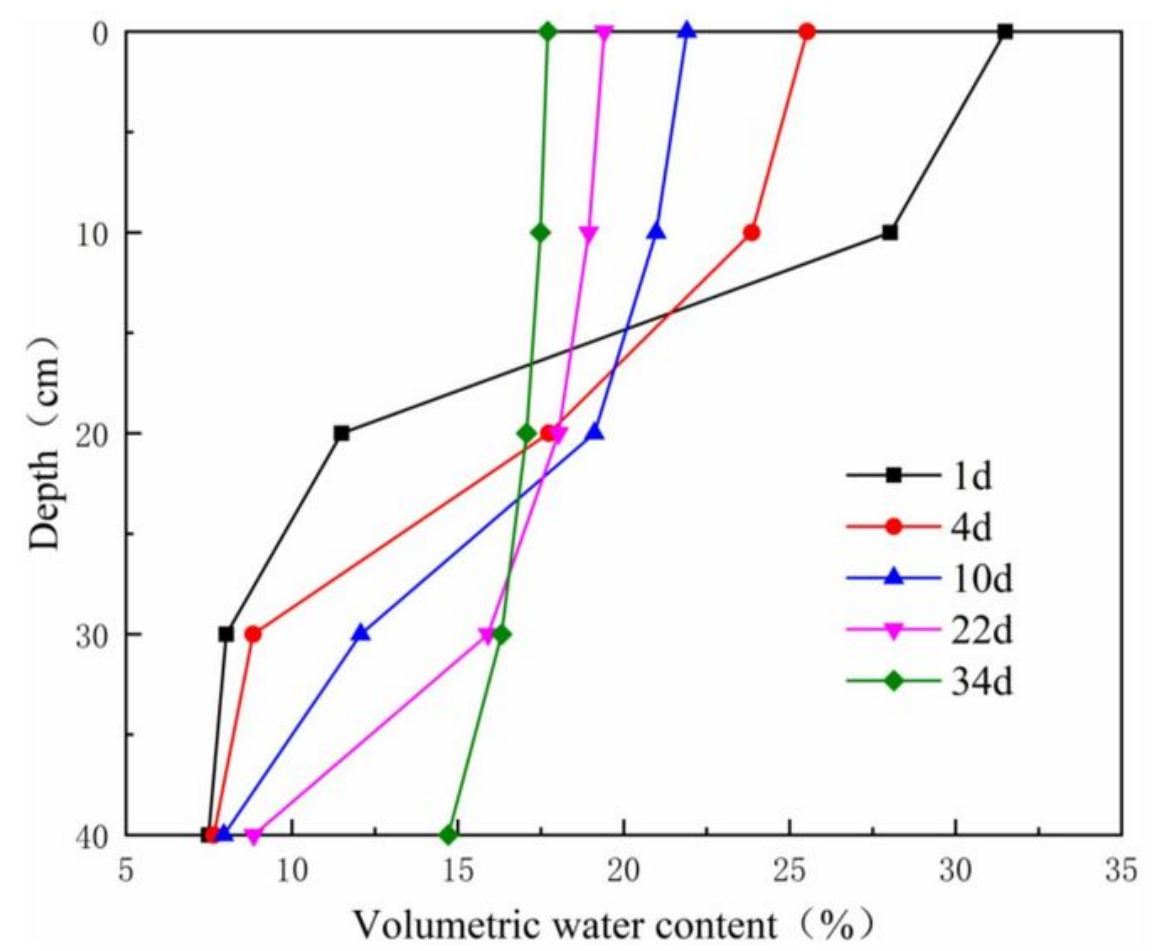

b

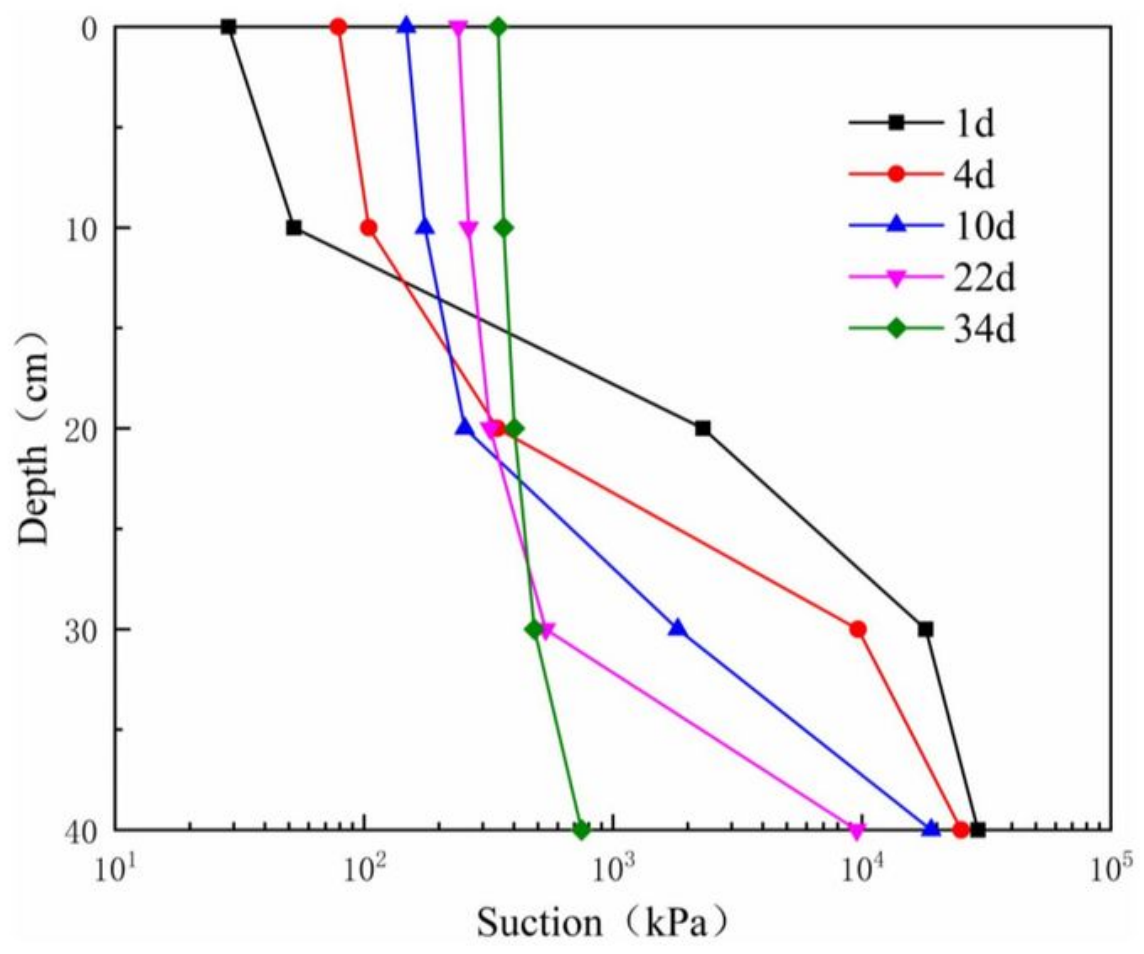

\section{Figure 7}

profile of water content (a) and suction (b). 
a
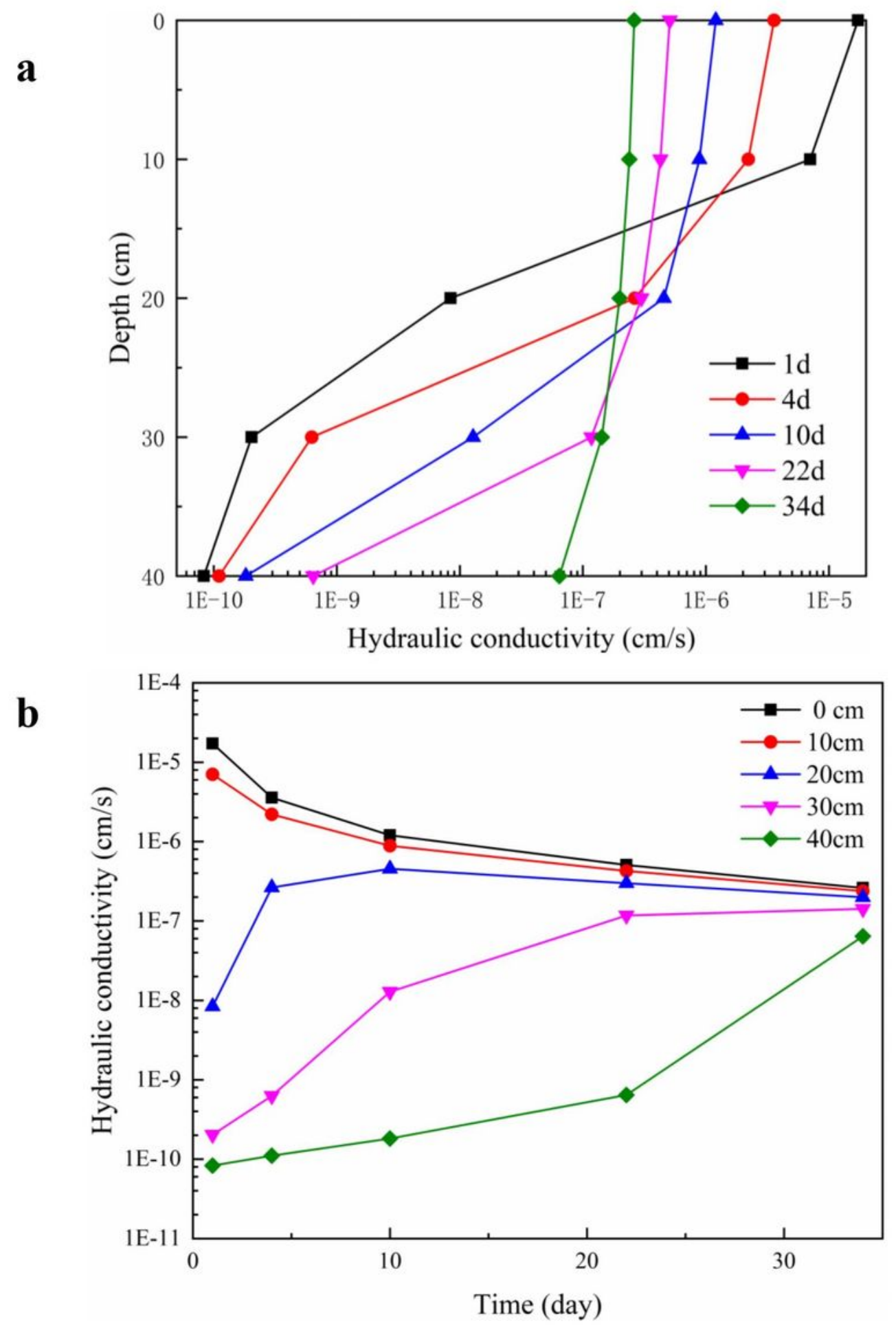

Figure 8

variation of hydraulic conductivity with depth (a) and time (b). 

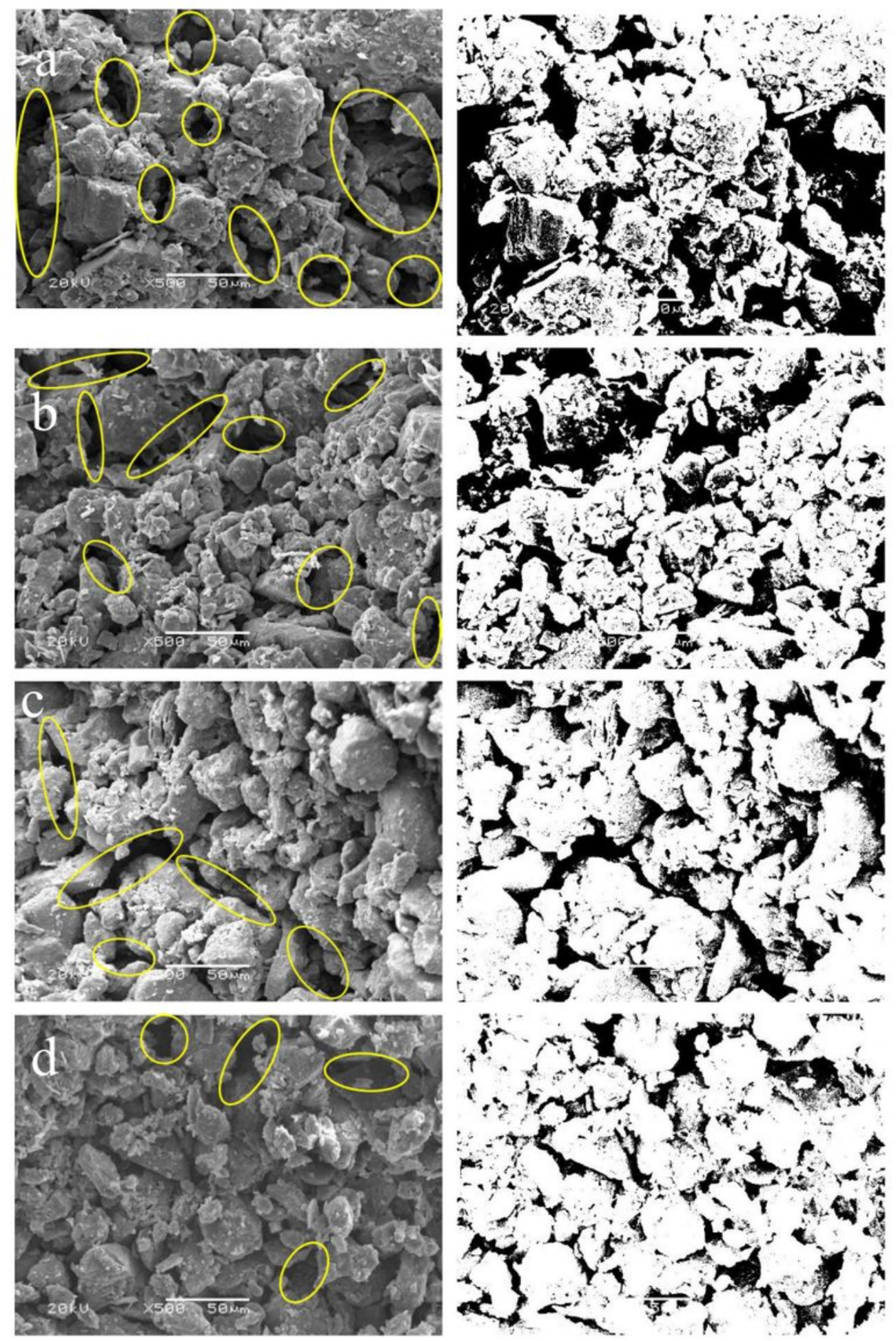

Figure 9

Microstructure photos and binarization photos of soil samples at different depths. (a) $10 \mathrm{~cm}$. (b) $20 \mathrm{~cm}$. (c) $30 \mathrm{~cm}$. (d) $40 \mathrm{~cm}$. Yellow circles indicate interparticle pores. 


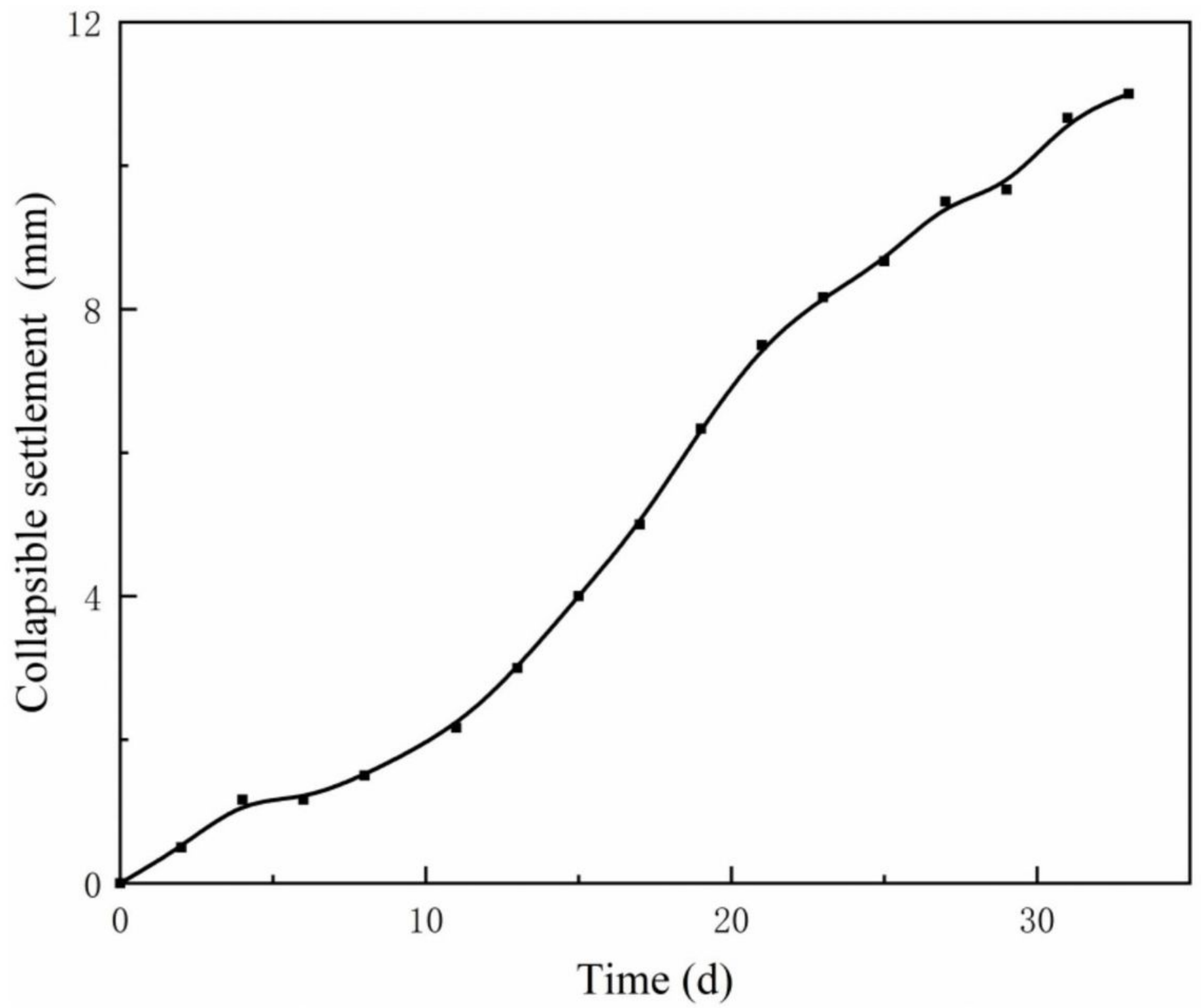

Figure 10

The relationship between settlement displacement and seepage time. 


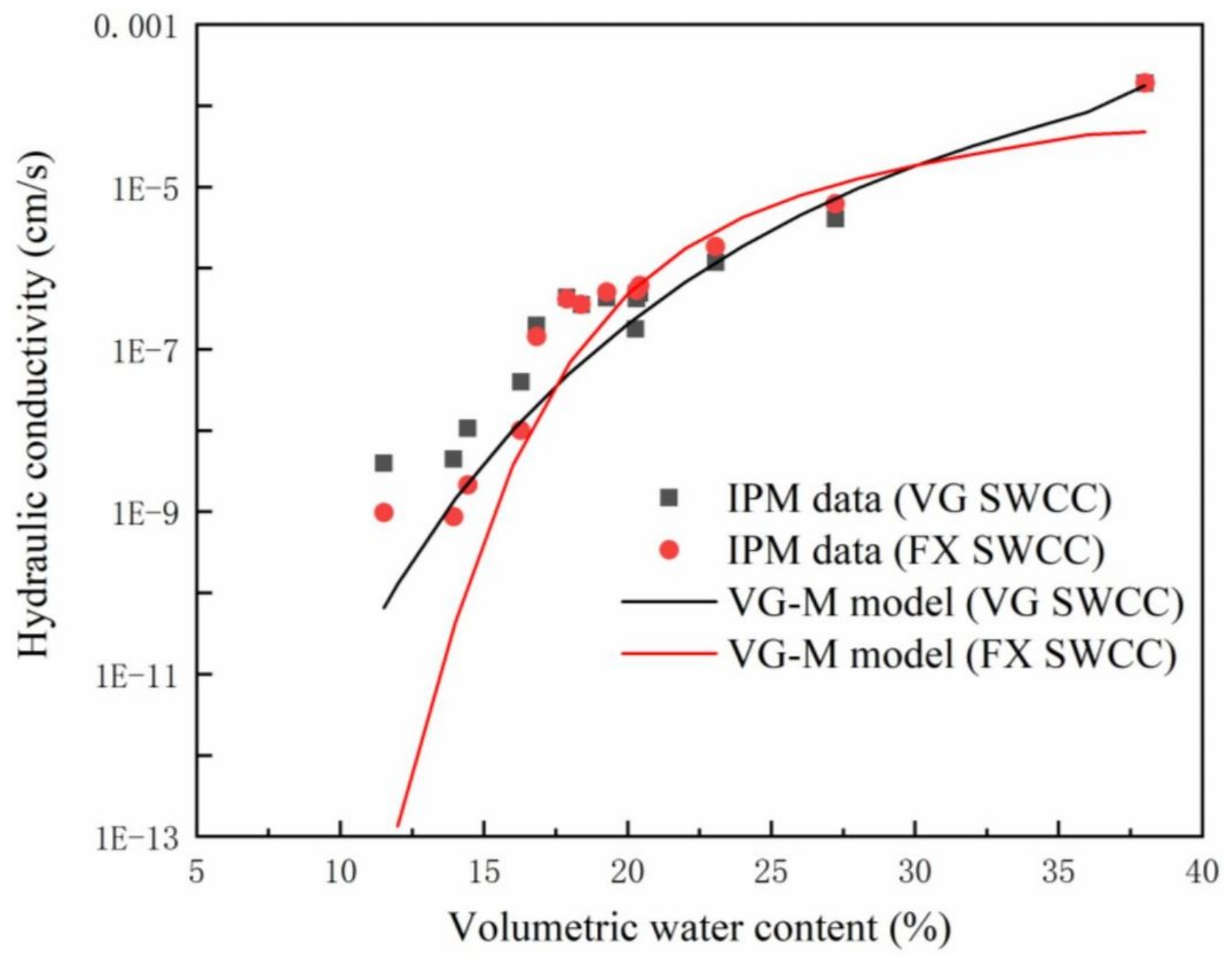

Figure 11

IPM data and VG-M model calculation results. 


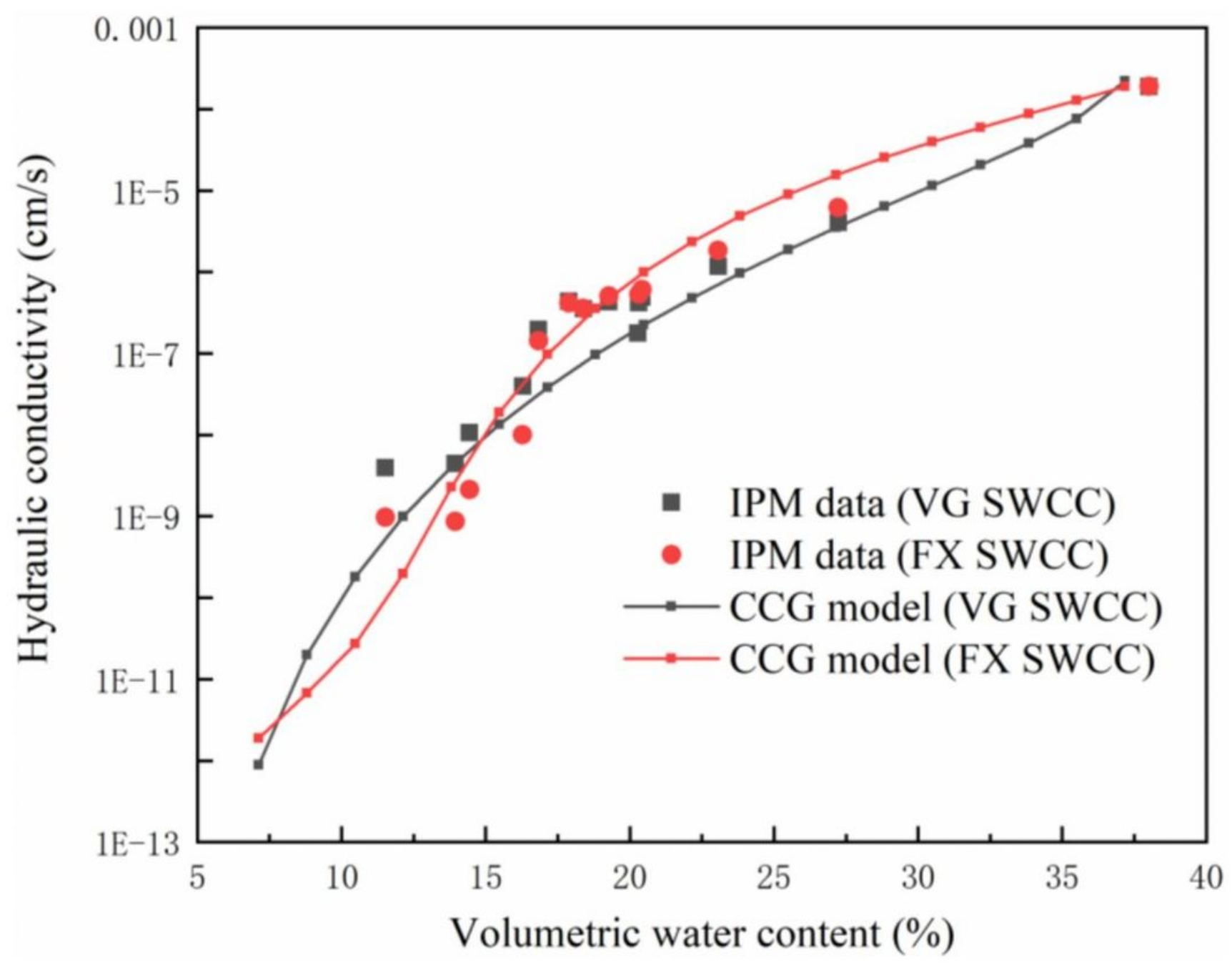

Figure 12

IPM data and CCG model calculation results.

\section{Supplementary Files}

This is a list of supplementary files associated with this preprint. Click to download.

- Table.docx 